\title{
An evaluation of the Positive Emotional Experiences Scale: A preliminary analysis
}

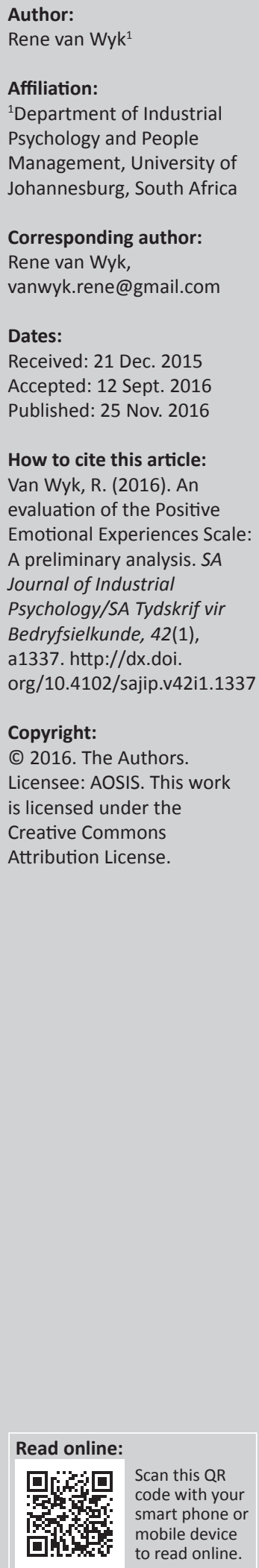

Orientation: The positive organisational behaviour movement emphasises the advantages of psychological strengths in business. The psychological virtues of positive emotional experiences can potentially promote human strengths to the advantages of business functioning and the management of work conditions. This is supported by Fredrickson's broadenand-build theory that emphasises the broadening of reactive thought patterns through experiences of positive emotions.

Research purpose: A preliminary psychometric evaluation of a positive measurement of dimensions of emotional experiences in the workplace, by rephrasing the Kiefer and Barclay Toxic Emotional Experiences Scale.

Motivation for the study: This quantitative Exploratory Factor Analysis investigates the factorial structure and reliability of the Positive Emotional Experiences Scale, a positive rephrased version of the Toxic Emotional Experiences Scale.

Research approach, design and method: This Exploratory Factor Analysis indicates an acceptable three-factor model for the Positive Emotional Experiences Scale. These three factors are: (1) psychological recurrent positive state, (2) social connectedness and (3) physical refreshed energy, with strong Cronbach's alphas of 0.91, 0.91 and 0.94 , respectively.

Main findings: The three-factor model of the Positive Emotional Experiences Scale provides a valid measure in support of Fredrickson's theory of social, physical and psychological endured personal resources that build positive emotions.

Practical/Managerial implications: Knowledge gained on positive versus negative emotional experiences could be applied by management to promote endured personal resources that strengthen positive emotional experiences.

Contribution/value-add: The contribution of this rephrased Positive Emotional Experiences Scale provides a reliable measure of assessment of the social, physical and endured psychological and personal resources identified in Fredrickson's broaden-and-build theory. Application of this Positive Emotional Experiences Scale as a diagnostic tool may allow businesses to work towards more positive emotional experiences in the workplace.

\section{Introduction}

\section{The positive psychological movement}

With the development of the positive psychology movement, businesses have become more aware of the advantages thereof and the necessity to nurture positive organisational behaviour (Luthans, 2002; Meyers, Van Woerkom \& Bakker, 2013). The positive psychology movement initiated by Seligman $(1998,1999)$ places emphasis on personal strengths, in contrast to the psychology discipline that has historically concentrated on pathology. This positive psychology movement regards the illness ideology and negative connotations of traditional clinical psychology as outdated (Seligman \& Csikszenthmihalyi, 2000). The adoption of a positive psychological approach could potentially prevent psychopathology, emphasising human strengths in all its facets (Maddux, 2008), promoting quality of life (Seligman \& Csikszenthmihalyi, 2000).

The positive psychological movement initiated by Seligman $(1998,1999)$ was preceded as behavioural self-management practices (Davis \& Luthans, 1980; Luthans \& Davis, 1979), followed by positive organisational behaviour (Luthans, 2002). This concept was extended by introducing the notion of psychological capital (Luthans, Luthans \& Luthans, 2004; Luthans, Youssef \& Avolio, 2007) described as the (1) efficacy (confidence) in being successful in challenging situations; (2) optimism in making positive attributions towards future successes; (3) demonstrating hopeful 
behaviour through goal directed pathways to succeed; and (4) signifying resilience in attaining success in the face of adversity. The application of behavioural self-management practices in the advancement of psychological capital provides the opportunity to improve performance and satisfaction (Luthans, Avey, Clapp-Smith \& Li, 2008; Luthans, Avolio, Avey \& Norman, 2007a). Positive organisational behaviour may promote the psychological capital virtues of the individual to the advantage of the business (Luthans, 2012; Luthans et al., 2007). Psychological capital virtues and its underlying positive emotions are necessary in effective daily organisational functioning.

\section{Positive emotions and organisational outcomes}

Positive emotions may hold many advantages for individuals in an organisation. Positive emotions are defined as seeking opportunities of good feelings of joyful, inspirational, grateful and serene states (Fredrickson \& Kurtz, 2011). The relationship between positive emotions and organisational outcomes are reported in the following studies: Increased positive affect significantly predicts organisational citizenship behaviour and task performance, when respectively associated with a downshift and upshift in negative affect (Yang, Simon, Wang \& Zheng, 2016). The tendency to express positive emotional behaviours contributes to favourable experiences by customers (Fischer, 2014), satisfaction with corporate social responsibility activities (Onkila, 2015), an increase of prosocial behaviour (Cavanaugh, Bettman \& Luce, 2015) and enhanced team member exchange (Tse \& Dasborough, 2008), as well as assists in making sense of the experiences in business failure (Byrne \& Shepherd, 2015). The ability to control the emotions of other people within a work team plays a moderating role in performance (Collins, Jordan, Lawrence \& Troth, 2016). With an increase of personal wellbeing resources, a negative relationship forms with stress symptoms and turnover intention (Siu, Cheung \& Lui, 2015). These positive outcomes could be important in an organisational setting and may result in many advantages on individual and organisational level.

\section{Beneficial outcomes of positive emotional experiences writ large and their possible benefit to business}

Positive emotions seem to have personal and social consequences. Ideally organisations should make use of positive psychology interventions that promote different forms of employee well-being and potential performance (Meyers et al., 2013). Such interventions should include proficiency in building social relationships through communication and solving problems (Smith \& HollingerSmith, 2015). It is reasoned that although negative emotions should be acknowledged and managed, the promotion of positive emotions could be beneficial. The capitalisation of positive experiences could enhance overall psychological well-being in an organisation. Organisations could contribute in preserving a culture of positive emotions and tailoring the philanthropic management of emotions (Koskina \& Keithley,
2010), thereby reaping the benefits. This may lead organisations to become functional in practising the broadenand-build theory characterised by endured social, physical, intellectual and psychological reserves (Fredrickson, 2001).

Different indications of the nurturing of positive emotions may play an advantageous role in business. Evidence suggests that positive emotions increase with the nurturing of self-enhancement strategies (Ouweneel, Le Blanc \& Schaufeli, 2013). Emotional self-regulation leads to an increase in both psychological well-being and physical health (Heiy \& Cheavens, 2014). The nurturing of positive affect potentially leads to endured positive thinking and cognitive processing (Strauss \& Allen, 2006). A tendency towards positive affect may be useful in the resolution of conflict (Cohrs, Christie, White \& Das, 2013). Similarly, the savouring of beliefs in endured positive experiences show a significant positive relationship with resilience, happiness and life satisfaction, and significantly negatively related to depression (Smith \& Hollinger-Smith, 2015). Positive emotions are believed to enhance cognitive and social conduct, motivation, coping strategies, self-efficacy and resilience (Rowe, Fitness \& Wood, 2015). The practising of cognitive reappraisal techniques could reduce unhealthy emotional reactivity of individuals (Gruber, Hay \& Gross, 2014) and improve psychological well-being (Smith \& Hollinger-Smith, 2015). These features could improve the work relationships in organisations.

Businesses may also benefit from an environment that preserves constructive emotions. The conscious reappraisal of constructive emotions develops a sensitisation towards strategies that improve the regulation of unhealthy moods (Subic-Wrana et al., 2014). It broadens the cognisance of an increased association with emotional well-being (Fredrickson \& Joiner, 2002) and compensate for deficiencies, thereby leading to higher resilience (Smith \& Hollinger-Smith, 2015). Support of positive emotions includes the increase of dopamine levels, advancing the processing of cognitive control and resolution of conflict (Xue et al., 2013), an increase of tolerance thresholds of unpleasantness scores (Van Laarhoven et al., 2012) and advanced academic engagement (Ouweneel, Le Blanc \& Schaufeli, 2014). The up-regulation of positive emotions is positively related to different growth outcomes such as engagement, betterment of goal pursuits and growth, while it is negatively related to indulgence of substance and fantasy (Livingstone \& Srivastava, 2012). Positive emotions could also have a contagious positive effect and penetrate moods of others (Vijayalakshmi \& Bhattacharyya, 2012), which is necessary for the overall work culture in an organisation. This could prevent depressive states which are associated with a decrease in positive emotions (Gruber, Oveis, Keltner \& Johnson, 2011), with a high potential of positive influence on others (Vijayalakshmi \& Bhattacharyya, 2012).

The importance of identifying and measuring positive emotional experiences in the workplace is clear. The potential benefits of positive emotions and the ability to identify recurrent positive emotional states, of social connectedness 
and the regulation of refreshed energy are worth investigating. However, organisations and managers are not always aware of the state of emotional experiences in an organisation in order to take self-management actions. A tool to measure positive emotional experiences could therefore be useful. As far as could be established there is not an existing scale that measures positive emotional experiences on more than one dimension.

The contribution of this article is fourfold. First, the Kiefer and Barclay's (2012) Toxic Emotional Experiences Scale is rephrased by formulating the existing items into positive emotional experiences statements and pilot tested by a group of experts. Second, this rephrased Positive Emotional Experiences Scale of the Kiefer and Barclay's (2012) Toxic Emotional Experiences Scale provides a more differentiated measure of positive emotional experiences, measuring more than one factor. Third, this rephrased Positive Emotional Experiences Scale provides the opportunity to businesses to evaluate the level of positive emotional experiences of their employees and in the business culture in general. Fourth, this revised Positive Emotional Experiences Scale potentially provides opportunities for self-reflection on and rehabilitation of the growth potential of constructive emotions, on both the organisational and individual level.

\section{The theory of positive emotions}

While positive psychology verifies and explains dynamics that contribute to how individuals 'flourish' (Seligman \& Csikszenthmihalyi, 2000), positive emotions support the psychological growth and well-being that develops the capacity to flourish (Fredrickson, 2001). Broadened thinking of positive emotions contributes towards an upward spiral of improved emotional welfare (Fredrickson \& Joiner, 2002). Fredrickson (2001) interprets the phenomenon of unique positive emotions through the positive emotions' broadenand-build theory. Emotions are described as differing from affect (Fredrickson, 2001). Emotions are regarded as distinct from affect, where affect is seen as more long-lasting and conscious than emotions. Emotions are viewed as the multicomponent tendencies that develop in a brief period, as an individual consciously or unconsciously ascribe personal meaning to an event leading to response tendencies embedded in physiological responses and cognitive processes.

The broaden-and-build theory is an explanation of the contribution of distinct idiosyncrasies of positive emotions in broadening an individual's reactive thought-actions (Fredrickson, 2001). Consequently reactive thought-actions assist in building a broad variety of endurance resources, that is, physical, intellectual, social and psychological. In contrast, by nurturing negative emotions, results in an opposite effect leading to a narrowed self-perpetuating downward spiral of depression, pessimism and negative emotions (Fredrickson \& Joiner, 2002). According to this theory, 'discrete positive emotions', such as 'joy, interest, contentment, pride and love' (Fredrickson, 2001, p. 219), broaden the repertoire of an individual's momentary thought-actions. This would advance

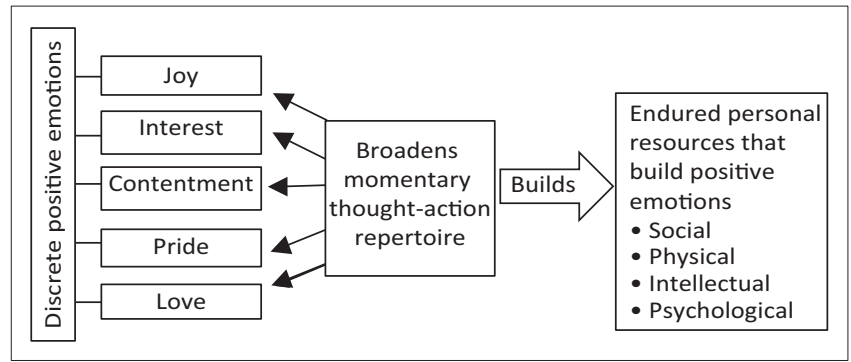

FIGURE 1: Model based on Fredrickson's (2001) broaden-and-build theory.

the possibility that an individual would act with positive emotions in future situations (Fredrickson \& Joiner, 2002). Consequently, the nurturing of positive emotions should build endurance on a social, physical, intellectual and psychological level. Figure 1 provides an interpretation of Fredrickson's (2001) broaden-and-build theory.

According to the model in Figure 1, discrete positive emotions, as described by Frederickson (2001), represent love, joy, content, interest, pride and love, and support an assortment of momentary thoughts. These thoughts of an individual shape and form endured personal resources (social, physical, intellectual and psychological). Such personal resources act as a durable reserve in managing challenges by undoing negative emotions and improving general emotional well-being. Thus, the nurturing and perpetuation of positive emotions could broaden the repertoire of momentary thought-actions which lead to enduring strengths on a social, physical, intellectual and psychological level.

\section{The relativity of positive and negative emotional experiences and the role of social construction in emotional experiences}

Positive and negative emotions are relative concepts and not cast in stone. For instance, Maddux (2008) argues that the illness ideology of clinical psychology is a socially constructed and not a scientifically proven fact. This argument emphasises the notion that emotions are not fixed. It also opens up the opportunity for change and rehabilitation, accentuating that individuals are not stuck in emotions and have the ability to actively take control of the enhancement of their personal well-being (Kaplan et al., 2014). The relativity of emotional responses is to a large extent prescribed by society, through cultural conditioning and beliefs maintained by socially constructed regulatory measures (Knyazev, Barchard, Razumnikova \& Mitrofanova, 2012; Miyamoto, Ma \& Petermann, 2014). For this reason, cultural and idiosyncratic differences of positive and negative thinking patterns are regarded as causal factors of psychological well-being (Diener et al., 2009). Accordingly the overall higher levels of life satisfaction in cultures that assess states of positive emotion as important (Bastian, Kuppens, De Roover \& Diener, 2014). Should individuals realise the relativity and social influence of emotional reactions, the possibility of taking control of the rehabilitation and stabilisation of their emotions could increase. Catalino, Algoe and Fredrickson 
(2014) coined the term prioritising positivity to explain the habit of daily giving precedence to positive emotional selfregulation strategies. This delicate prioritising of positivity leads to resilience and frequent positive emotional experiences. It is, however, important to view positive and negative emotional experiences in balance.

\section{Cultivation of positive emotions through behavioural self-management}

The study of emotions and emotional contamination has gained increased importance in investigating organisational behaviour and operation (Liang \& Steve Chi, 2013; Vijayalakshmi \& Bhattacharyya, 2012). In the early 1980s, Davis and Luthans (1980) emphasised that organisations should realise that emotional responses are manageable through behavioural self-management. This implies that emotional self-regulation is fundamentally important in the effectiveness of the organisational functioning (Davis \& Luthans, 1980; Luthans \& Davis, 1979). Luthans and Davis (1979, p. 43) define behavioural self-management as 'the deliberate regulation of stimulus cues, covert processes, and response consequences to achieve personality identified behavioural outcomes'. Organisations could benefit from being more aware of the positive emotional virtues of individuals as these shape endured personal resources, such as psychological well-being (Rothmann, Steyn \& Mostert, 2005), greater happiness, life satisfaction and less depression (Smith \& Hollinger-Smith, 2015).

\section{The regulation and application of positive affect in the workplace}

The study of emotions and emotional contamination has gained increased importance in investigating organisational behaviour and operation (Liang \& Steve Chi, 2013; Vijayalakshmi \& Bhattacharyya, 2012). The application of practical psychology is often out of the reach of management (Axelrod, 2015). Self-management practices that promote positive affect in the workplace provide the opportunity to management to practically apply positive organisational behaviour. Positive affect is for instance significantly positively related to positive attentional bias, psychological well-being and life satisfaction and significantly negatively related to weak attentional bias and depression ( $\mathrm{Xu}$ et al., 2015). The evaluation of worker's emotional experiences and necessary change management strategies could be beneficial to a business (Steigenberger, 2015) and team performance (Collins et al., 2016). The cognition of positive emotional experiences seems to significantly contribute to the successful guidance of future appraisal strategies when handling challenging situations (Levine, Schmidt, Kang \& Tinti, 2012). The regulation of emotions has an influence on the psychological and physiological reactions of an individual (Jackson, Malmstadt, Larson \& Davidson, 2000). Regulation of emotional responses through cognitive reappraisal strategies (Kim \& Hamann, 2007) and positive interaction (Maddux, 2008) is significant in the nurturing of mental health. An authentic positive work environment can be created by informally tailoring the philanthropic management of emotions (Koskina \& Keithley, 2010). This can be done by consciously engaging in actions that nurture support and care. All in all positive emotional experiences could thus be utilised to the advantage of a business.

\section{A balanced view of negative and positive emotional experiences}

Positive psychology and the emphasis on positive emotions do not imply that pathology and negative emotional experiences should be ignored. Positive emotions, despite their positive influence, may potentially also have negative consequences when negative states are not acknowledged and dealt with. Similarly positive and negative emotions should not simply regarded as aligned with positive and negative outcomes, as it could have contrasting outcomes (Lindebaum \& Jordan, 2012). For instance, powerful positive emotions could be interpreted as arrogance, while powerful negative emotions could be interpreted as an authentic response to an unhealthy situation (Lindebaum \& Jordan, 2012). Catalino et al. (2014) warn that unrealistic and obsessive inflated positive emotions may backfire as it is often not sustainable. As sustainability deteriorates, it leads to feelings of despondency.

It is especially important that both positive and negative emotions are acknowledged and addressed in business. Cohrs et al. (2013) warn that positive psychology potentially has adverse effects when it does not necessarily serve all parties. The lack of acknowledgement of negative emotions could have antagonistic outcomes and snowball into toxic emotions and pathology with detrimental consequences for a business (Kiefer \& Barclay, 2012) and burnout (Quinones, Rodriguez-Carvajal, Clarke \& Griffiths, 2016). Sharing negative emotions socially, could lead to positive emotional outcomes and social integration (Yang \& Kelly, 2016) and healthy positive outcomes (Quinones et al., 2016). The constructive expression of negative emotions could improve important exchange of knowledge that may improve project performance (Stephens \& Carmeli, 2016). The importance of acknowledging negative emotions is evident as negative repercussions may follow when negative states are not addressed (Cohrs et al., 2013), leading to diminished psychological health, deteriorating views towards the workplace and diminished performance (Kiefer \& Barclay, 2012). Similarly the existence of positive affect is on its own not effective in business. The productive self-management and reciprocal management of team members' emotional reactions is necessary to optimise performance, especially when tasks are complex (Collins et al., 2016). Thus, the identification and acknowledgement of negative emotions and remedial processes are necessary to establish a healthy work environment. When knowledge is gained concerning negative states, it can serve as motivation to take the necessary precautionary action.

This is thus a stern warning that the regulation of positive emotions on an organisational level should not serve as a mechanism to ignore or deny negative emotional experiences 
(Cohrs et al., 2013). For instance, negative emotions often explain an individual's lack of work engagement (Kiefer \& Barclay, 2012). Knowledge of negative states could prevent pathology. When individuals are able to identify negative states, they can act pre-emptively, with discretion, and consequently conserve their energy appropriately. A society with low emotional awareness regulation strategies seems to promote maladaptive emotional behaviours (Subic-Wrana et al., 2014) that would jeopardise harmony in a business. On the contrary, positive emotions promote subjective wellbeing and life satisfaction (Bastian et al., 2014; Weytens, Luminet, Verhofstadt \& Mikolajczak, 2014), which are very beneficial to an organisation. Should a business create a culture that is sensitive to both positive and negative emotions, discretionary coping mechanisms are developed which act as a safeguard in a supportive culture (Kiefer \& Barclay, 2012). Because of the importance of acknowledging both positive and negative emotions, Knyazev et al. (2012) suggest that scientific enquiry should take both into account when investigating the relationships of emotions with other variables.

\section{Measurement of positive and negative emotional experiences}

Kiefer and Barclay (2012) developed a Toxic Emotional Experiences Scale. These authors argue that negative emotions can be detrimental to the individual in the work situation as they lead to adverse toxic emotional experiences. Toxic emotional experiences are defined as evolving from short-lived negative emotions, to a sustained affective state that is (1) psychologically recurring and unresolved, (2) causes disconnection from one's personal social network, and (3) physically and psychologically draining (Kiefer \& Barclay, 2012). It is proposed that positive emotional experiences is regarded as a long-lasting psychologically recurring affective state, resulting in being associated with one's personal social network, which is physically and psychologically uplifting. It is argued that positive and negative emotions should not be regarded as two opposing ends of a continuum, rather two unrelated dimensions (Todorova, Bear \& Weingart, 2014), that are discreet (Fredrickson, 2001). The discussion above emphasises the importance of also measuring the experience of positive emotions. Healthy emotions are seen to benefit individuals by potentially spreading positive emotions in an organisation (Vijayalakshmi \& Bhattacharyya, 2012). A measure of both positive and negative emotional experiences could be beneficial as it could provide information on current states and opportunities of improvement.

\section{Rationale for rephrasing the Kiefer and Barclay's (2012) Toxic Emotional Experiences Scale}

Existing positive and negative emotional scales are the Positive and Negative Affect Scale (PANAS) (Watson, Clark \& Tellegen, 1988), Diener et al.'s (2009) Scale of Positive and Negative Experiences (SPANE) that measures feelings, and the Diener et al.'s (2009) Positive Thinking Scale (PTS) that measures positive and negative attitudes. These scales measure positive and negative emotions or experiences on single dimensions, as either positive or negative. The Kiefer and Barclay's (2012) Toxic Emotional Experiences Scale is more differentiated, measuring different forms of negative emotions on three factors, namely psychologically recurring, disconnecting socially and draining emotional states. The Kiefer and Barclay's (2012) Toxic Emotional Experiences Scale is as far as could be established, the only scale that measures negative emotions on more than one dimension. A similar differentiated measure of positive emotional experiences is needed. It therefore proposed to rephrase the Kiefer and Barclay's (2012) scale into a Positive Emotional Experiences Scale to measure a positive psychological state, social connectedness and physical refreshed energy. Such a positive measure would provide a more balanced measure of both positive and negative emotional experiences. If both positive and toxic negative emotions are seen in balance, the advantages of the positive alternative could become a more attractive ideal to aspire to. In this way, personal and organisational challenges may be bridged more effectively. With a Positive Emotional Experiences Scale individuals and businesses could work on developing a positive behaviour cycle that perpetuates positive organisational behaviour. Such a positive scale could provide the platform for striving to work proactively towards positive outcomes and the management of negative emotions and its sources.

By rephrasing and validating the Kiefer and Barclay's (2012) Toxic Emotional Experiences Scale into positive terms, businesses would be provided with a tool to assess positive emotional experiences. This is important, seen in the light that other positive and negative emotion scales measure only one dimension, opposed to the Kiefer and Barclay's (2012) Toxic Emotional Experiences Scale that measures three dimensions. This study aims to give clarity on the internal consistency and reliability of the positively phrased version of the Kiefer and Barclay's (2012) Toxic Emotional Experiences Scale. Clarity is aimed at determining the acceptability of the item loadings of the three proposed factors and determining the internal reliability of the factors. The contribution of the validation of such a scale is that it provides a springboard for the evolvement of a positive emotional experience scale on more than one dimension.

\section{Research method}

\section{Research approach}

This study is a quantitative, cross-sectional research design aimed at investigating the theoretic constructs of the Positive Emotional Experiences Scale by means of Principal Axis Factor Analysis. Principal Factor Analysis is used to provide a regression equation (operational definition) to test the theoretic nature of the underlying observed variables (Tabachnick \& Fidell, 2014). The Positive Emotional Experiences Scale was developed by rephrasing the Kiefer and Barclay's (2012) Toxic Emotional Experiences Scale into positive emotional statements. The aim was that it would represent three factors: psychological recurrent positive state, social connectedness and physical refreshed energy. 


\section{Research design}

\section{Participants and procedure}

Non-probability purposive sampling of heterogeneous groups (Saunders, Lewis \& Thornhill, 2012), were collected from white collar workers over different industries that ranged across different ethnical groups and positions. Participants were contacted by email and requested to answer the questionnaire via a web-based link. The sample of 265 participants had ages ranging between 21 and 74 . The majority were men $56.2 \%(n=149)$ and slightly fewer women $43.8 \%(n=116)$. The ethnicity of the participants was mainly white, $66.8 \%(n=177)$, followed by black, $17.4 \%(n=46)$, Coloured, $6 \%(n=16)$, Indian $4.9 \%(n=13)$, Asian 3\% $(n=8)$ and other, $1.9 \%(n=5)$. The primary language of the participants was mainly Afrikaans (52\%), followed by English (34\%) and a variety of indigenous languages (14\%). The educational level of participants ranged from individuals without Grade 12 (4.2\%), Grade 12 (18.1\%), Bachelor's degree or equivalent (25.3\%), Honours (11.7\%), Master's (23.8\%) and $\mathrm{PhD}(17.0 \%)$. Most participants indicated their positions as professional $(31.3 \%)$, followed by middle management $(17.0 \%)$, administrative officer $(11.7 \%)$, senior manager $(8.7 \%)$, junior manager $(5.7 \%)$, executive $(4.2 \%)$, trainee/ intern (3.8\%), first level supervisor (3.0\%) and other (14.7\%).

\section{Measuring instrument}

The measuring instrument consisted of biographical variables, as well as the positively phrased version of the original Toxic Emotional Experiences Scale (Kiefer \& Barclay, 2012). The Kiefer and Barclay's (2012) Toxic Emotional Experiences Scale is measured by 18 items on a five-point scale ranging from (1) very rarely to (5) very often. The three factors of the Toxic Emotional Experiences Scale (Kiefer \& Barclay, 2012) consist of psychologically recurring $(\alpha=0.96)$, disconnecting $(\alpha=0.92)$ and draining $(\alpha=0.92)$ with data showing a good fit: $X^{2}=154.81, d f=60, p<0.001$; RMSEA $=$ 0.03 ; and CFI $=0.99$. An example of the psychologically recurring item: 'My negative emotional experiences are ongoing' (Kiefer \& Barclay, 2012, p. 607). The rephrased version in positive terms: Positive Emotional Experiences Scale consisted of 18 positively worded items based on the original toxic emotional experiences items. The positively worded items were reviewed by a sample of eight academic experts, who gave feedback in refining the statements. Items were representative of positive emotions representing (1) psychological recurring positive states, (2) social connectedness and (3) physical refreshed energy. For example, the item representing draining, phrased as 'I feel exhausted' (Kiefer \& Barclay, 2012, p. 607), was rephrased as 'I feel energetic'. The psychologically recurring item 'My negative emotional experiences are ongoing' was rephrased as 'I have continuous positive emotional experiences'. Similar to the original Kiefer \& Barclay (2012) scale, each item was answered on a 5-point Likert-type scale varying from very rarely (1) to very often (5). An Exploratory Factor Analysis was performed to validate the construct validity of the rephrased Positive Emotional Experiences Scale.

\section{Ethical considerations}

Participants were informed that participation was voluntary and that answers would go into a data system that is anonymous, and answers would be treated confidential. Participants were also assured that they could opt out at any time, should they decide to discontinue participation.

\section{Statistical analysis}

The IBM SPSS (2016) Version 23 programme was employed to conduct the analysis on the rephrased Positive Emotional Experiences Scale. Exploratory Factor Analysis was done to examine the items and determine the main factor structure (Cabrera-Nguyen, 2010). The communalities of each item were inspected to verify the acceptable level above 0.3 (Pallant, 2016). The eigenvalues, thus total variance of factors $>1.0$ and Scree test, combined with a parallel analysis were used to determine the factor extraction for further investigation. Descriptive statistics were investigated. There was evidence of excessive skewness in item 6. Baglin (2014) suggests polychoric correlation for normally distributed bivariate ordinal scale measures. Due to high correlation between factors, Principal Axis Factor Analysis, polychoric correlation, was used as extraction method, with A Direct Oblimin Oblique Rotation (Costello \& Osborne, 2005). Items that loaded less than 0.3 or cross loaded, with the difference between item loadings more than 0.3 , were deleted for further analyses. Cronbach Alpha coefficients determined the reliability of the scales, as proposed by Worthington and Whittaker (2006).

\section{Results}

\section{Exploratory Factor Analysis}

Exploratory Factor Analysis was done to assess for factor structure of the instrument. Items were inspected for KaiserMeyer-Olkin Measures of Sampling Adequacy and Bartlett's Test of Sphericity. Factorability fell within the limits of acceptable skewness coefficients as indicated in Table 1.

Table 1 indicates Kaiser-Meyer-Olkin Measures of Sampling Adequacy $=0.919$, above 0.6, and the Bartlett's Test of Sphericity $X^{2}=3953.317 ; d f=153$ at the significance level of $p=0.000$ in support of the factorability of the correlation matrix, as suggested by Pallant (2016). The communalities matrix indicated an explained variance of each item at an acceptable level above 0.3 (Pallant, 2016), with the exception of item 8 (See Table 2).

Monte Carlo Principle Component Analysis for Parallel Analysis indicated three factors higher than the criterion

TABLE 1: KMO and Bartlett's Test.

\begin{tabular}{llc}
\hline Test & Variable & Result \\
\hline $\begin{array}{l}\text { Kaiser-Meyer-Olkin } \\
\text { Measure of Sampling }\end{array}$ & - & 0.919 \\
Adequacy & \\
Bartlett's Test of Sphericity & Approximate Chi-Square & 3953.317 \\
& Degrees of freedom & 153 \\
& Sig. & 0.000 \\
\hline
\end{tabular}


value of 1.38. Kaiser's criterion implies the retention of eigenvalues above 1.0 (Pallant, 2016). Specifically, the three eigenvalues above 1 were 9.27, 2.15 and 1.38, respectively. The three factors explain a total of $71.07 \%$ of the cumulative variance (Factor 1: 51.5\%; Factor 2: 11.93\%: and Factor 3: $7.64 \%$ ) (see Table 3).

The scree plot showed a clear break between the third and fourth factors (see Figure 2).

Univariate descriptive statistics output for the 18 positive emotional experiences items was investigated and reported in Table 4.

Table 4 exhibits skewness of item 6 in excess of the threshold. After the initial factor analysis, three factors were retained for further investigation. R Studio was employed to run Principal Axis Factor Analysis polychoric correlation as suggested by Baglin (2014). Direct Oblimin Oblique Rotation was used as extraction method, due to high correlations between factors. The extraction and rotation methods were utilised to simplify factors and assess cut-offs of items (Tabachnick \& Fidell, 2014). Item 8 was removed in the first round, due to a communality value below 0.3 (Pallant, 2016). Item 14 was identified as a Heywood case, and was removed. The Heywood case could have been due to the small sample size (Tabachnick \& Fidell, 2014). In the following rounds, items 5 and 12 were removed individually because of crossloadings $>0.3$ (Tabachnick \& Fidell, 2014). Table 5 indicates

TABLE 2: Communalities of the factor loadings.

\begin{tabular}{llc}
\hline Item & Initial & Extraction \\
\hline $\begin{array}{l}\text { 1. I have continuous positive emotional } \\
\text { experiences }\end{array}$ & 1.000 & 0.782 \\
$\begin{array}{l}\text { 2. I feel sustained positive emotions } \\
\text { 3. My positive emotions keep reappearing }\end{array}$ & 1.000 & 0.796 \\
$\begin{array}{l}\text { 4. My positive emotions re-surfaces in } \\
\text { different situations }\end{array}$ & 1.000 & 0.821 \\
$\begin{array}{l}\text { 5. My positive emotions overcome negative } \\
\text { emotions }\end{array}$ & 1.000 & 0.699 \\
$\begin{array}{l}\text { 6. I enjoy other's company } \\
\text { 7. I am a social person }\end{array}$ & 1.000 & 0.600 \\
\hline $\begin{array}{l}\text { 8. I am never lonely } \\
\text { 9. I feel connected to people }\end{array}$ & 1.000 & 0.715 \\
10. I am interested in socializing with others & 1.000 & 0.766 \\
$\begin{array}{l}\text { 11. I enjoy interacting with others } \\
\text { 12. Other people pay attention to me }\end{array}$ & 1.000 & 0.252 \\
\hline 13. I feel energetic & 1.000 & 0.639 \\
14. My energy levels are great & 1.000 & 0.799 \\
\hline 15. I feel connected to my work & 1.000 & 0.815 \\
16. I feel active & 1.000 & 0.548 \\
17. I am enthusiastic & 1.000 & 0.802 \\
18. I am inspired by my work & 1.000 & 0.770 \\
\hline & 1.000 & 0.732 \\
\hline
\end{tabular}

the factor loadings on the three scales after the removal of the four items.

The inter-correlation between the factors, reported in Table 6 , were $r=0.50$ between Factors 1 and 2, $r=0.65$ between Factors 1 and 3 and $r=0.44$ between Factors 2 and 3 .

The factor correlation matrix in Table 6 indicates the correlation between factors as high. This supports the notion of using Principal Axis Factor Analysis as suggested by Tabachnick and Fidell (2014).

After the Exploratory Factor Analysis, Cronbach Alpha coefficients were determined as proposed by Worthington and Whittaker (2006) as a common method of developing and validating a newly developed scale. The Cronbach Alpha internal consistencies of the three-factor model were all above the 0.7 preferable value as suggested by Pallant (2016). The Cronbach Alpha coefficients of the three factors are Factor 1: psychological recurrent positive state $(\alpha=0.93)$, Factor 2: social connectedness $(\alpha=0.91)$ and Factor 3: physical refreshed energy $(\alpha=0.91)$.

\section{Discussion}

The objective of the study was to provide a valid and reliable measure of assessment of a Positive Emotional Experiences Scale as defined in Fredrickson's broaden-and-build theory. Exploratory Factor Analysis of the positive emotional experiences rephrased Kiefer and Barclay's (2012) Toxic Emotional Experiences Scale identified four problematic items:

- The low communality of Item 8: 'I am never lonely', is an indication that the item is not interpreted as 'connectedness'. A more positive phrasing of the original item: 'I tend to feel alone' such as 'I mostly feel connected to people' would probably have been more representative of the connectedness factor. Both items 5 and 12 were deleted because of high cross-loadings.

- Item 5: 'My positive emotions overcome negative emotions' loaded on both psychological recurrent positive state and physical refreshed energy. The original item read: 'some negative emotional experiences just will not go away'. A more representative phrase for psychological recurrent positive state could be: 'I often experience positive emotions'.

- Item 12 originally read 'others tend to ignore me' and was rephrased as 'other people pay attention to me', loaded on both social connectedness and psychological recurrent positive state. An alternative phrasing to represent

TABLE 3: Eigen values and total explained variance.

\begin{tabular}{|c|c|c|c|c|c|c|}
\hline \multirow[t]{2}{*}{ Component } & \multicolumn{3}{|c|}{ Initial Eigenvalues } & \multicolumn{3}{|c|}{ Extraction Sums of Squared Loadings } \\
\hline & Total & $\%$ Variance & Cumulative $\%$ & Total & $\%$ Variance & Cumulative $\%$ \\
\hline 1 & 9.27 & 51.50 & 51.50 & 9.27 & 51.50 & 51.50 \\
\hline 2 & 2.15 & 11.93 & 63.43 & 2.15 & 11.93 & 63.43 \\
\hline 3 & 1.38 & 7.64 & 71.07 & 1.38 & 7.64 & 71.07 \\
\hline
\end{tabular}




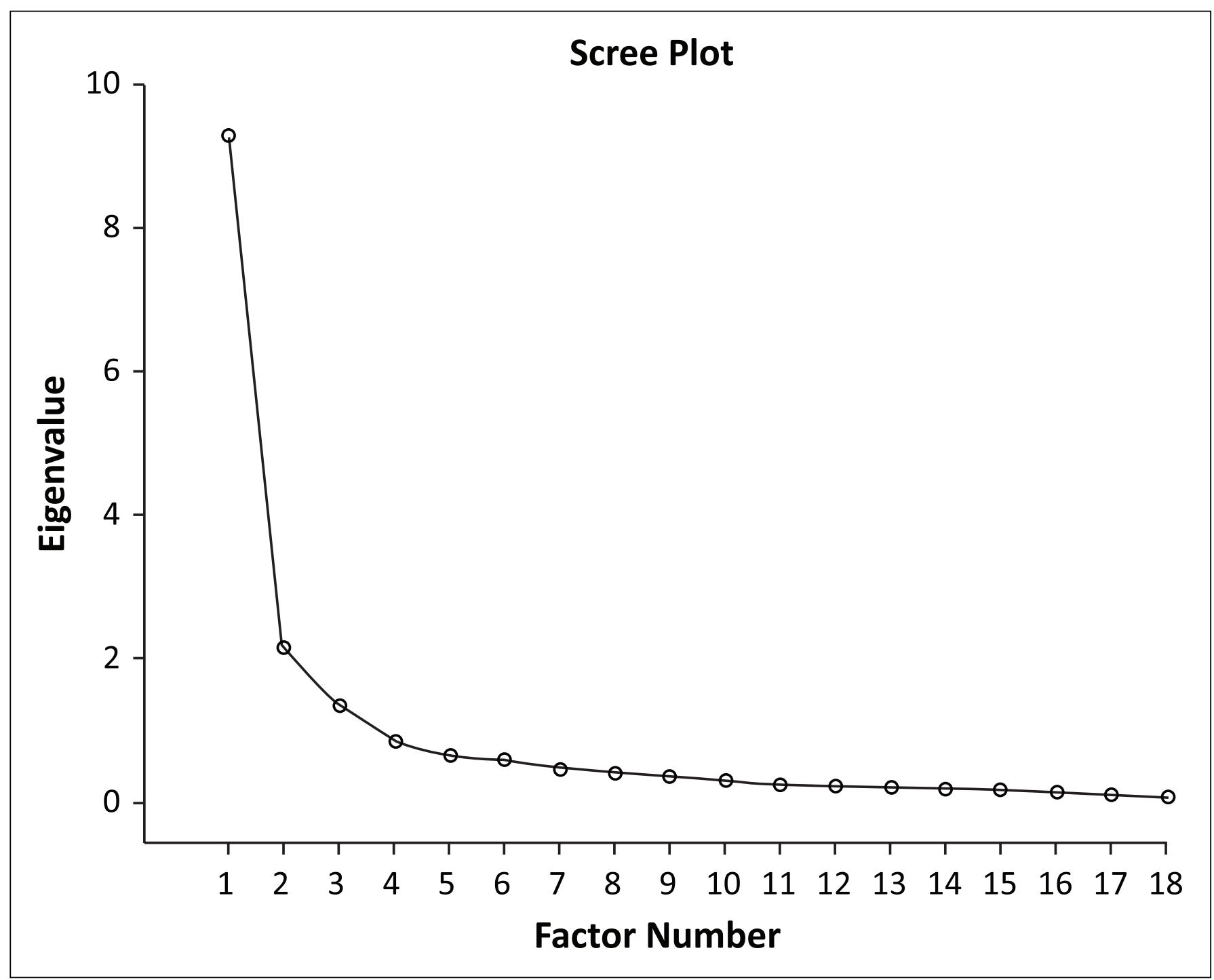

FIGURE 2: Scree plot and extracted eigenvalues suggest a three-factor solution.

TABLE 4: Factor's Univariate descriptive statistics output for the 18 positive emotional experiences items.

\begin{tabular}{|c|c|c|c|c|c|}
\hline Variable & Mean & Confidence interval & Variance & Skewness & Kurtosis \\
\hline 1 & 3.56 & (3.43 3.69) & 1.156 & -0.71 & -0.23 \\
\hline 2 & 3.48 & (3.36 3.61) & 1.084 & -0.60 & -0.30 \\
\hline 3 & 3.60 & (3.47 3.72) & 1.090 & -0.53 & -0.49 \\
\hline 4 & 3.64 & (3.52 3.76) & 0.959 & -0.68 & -0.11 \\
\hline 5 & 3.65 & (3.52 3.78) & 1.159 & -0.79 & 0.04 \\
\hline 6 & 3.89 & (3.78 4.01) & 0.951 & -1.08 & 0.98 \\
\hline 7 & 3.57 & (3.44 3.71) & 1.268 & -0.59 & -0.46 \\
\hline 8 & 3.32 & (3.18 3.47) & 1.364 & -0.31 & -0.93 \\
\hline 9 & 3.70 & (3.58 3.82) & 0.945 & -0.83 & 0.36 \\
\hline 10 & 3.67 & (3.54 3.80) & 1.109 & -0.75 & -0.10 \\
\hline 11 & 3.89 & (3.77 4.02) & 1.012 & $-0.99 c ̧$ & 0.52 \\
\hline 12 & 3.76 & (3.65 3.88) & 0.886 & -0.84 & 0.59 \\
\hline 13 & 3.63 & (3.50 3.75) & 1.091 & -0.66 & -0.16 \\
\hline 14 & 3.51 & (3.38 3.64) & 1.190 & -0.46 & -0.59 \\
\hline 15 & 3.78 & (3.65 3.91) & 1.189 & -0.83 & 0.05 \\
\hline 16 & 3.63 & $(3.503 .76)$ & 1.242 & -0.58 & -0.50 \\
\hline 17 & 3.84 & (3.72 3.96) & 1.005 & -0.92 & 0.47 \\
\hline 18 & 3.68 & (3.54 3.81) & 1.311 & -0.69 & -0.36 \\
\hline
\end{tabular}


TABLE 5: Principal Axis Direct Oblimin Oblique Rotation, polychoric correlation, for the three-factor solution of the Positive Emotional Experiences Scale.

\begin{tabular}{|c|c|c|c|}
\hline Item & $\begin{array}{l}\text { Psychological } \\
\text { recurrent } \\
\text { positive state }\end{array}$ & $\begin{array}{l}\text { Social connected- } \\
\text { ness }\end{array}$ & $\begin{array}{c}\text { Physical } \\
\text { refreshed energy }\end{array}$ \\
\hline $\begin{array}{l}\text { 1. I have continuous positive } \\
\text { emotional experiences }\end{array}$ & -0.01 & -0.01 & 0.89 \\
\hline $\begin{array}{l}\text { 2. I feel sustained positive } \\
\text { emotions }\end{array}$ & 0.00 & 0.02 & 0.88 \\
\hline $\begin{array}{l}\text { 3. My positive emotions keep } \\
\text { reappearing }\end{array}$ & 0.06 & -0.03 & 0.85 \\
\hline $\begin{array}{l}\text { 4. My positive emotions } \\
\text { re-surfaces in different } \\
\text { situations }\end{array}$ & 0.03 & 0.05 & 0.71 \\
\hline 6. I enjoy other's company & -0.02 & 0.72 & 0.21 \\
\hline 7. I am a social person & -0.07 & 0.88 & 0.02 \\
\hline 9. I feel connected to people & 0.13 & 0.63 & 0.13 \\
\hline $\begin{array}{l}\text { 10. I am interested in } \\
\text { socializing with others }\end{array}$ & 0.00 & 0.95 & -0.10 \\
\hline $\begin{array}{l}\text { 11. I enjoy interacting with } \\
\text { others }\end{array}$ & 0.10 & 0.85 & -0.01 \\
\hline 13. I feel energetic & 0.73 & 0.15 & 0.02 \\
\hline $\begin{array}{l}\text { 15. I feel connected to my } \\
\text { work }\end{array}$ & 0.93 & -0.11 & 0.02 \\
\hline 16. I feel active & 0.91 & 0.02 & -0.07 \\
\hline 17. I am enthusiastic & 0.76 & 0.14 & 0.07 \\
\hline 18. I am inspired by my work & 0.82 & -0.04 & 0.07 \\
\hline Cronbach Alpha Coefficient & 0.93 & 0.91 & 0.91 \\
\hline
\end{tabular}

TABLE 6: Pearson Product-Moment Correlation Matrix.

\begin{tabular}{lccc}
\hline Factor & $\begin{array}{c}\text { Psychological } \\
\text { recurrent positive } \\
\text { state }\end{array}$ & $\begin{array}{c}\text { Social } \\
\text { connectedness }\end{array}$ & $\begin{array}{c}\text { Physical refreshed } \\
\text { energy }\end{array}$ \\
\hline $\begin{array}{l}\text { Psychological recurrent } \\
\text { positive state }\end{array}$ & 1.000 & 0.50 & 0.71 \\
Social connectedness & 0.50 & 1.000 & 0.44 \\
Physical refreshed energy & 0.71 & 0.44 & 1.000 \\
\hline
\end{tabular}

connectedness, would be: 'I easily get attention from other people'.

- Item 14 in the original scale reads: 'My energy level decreases immediately'. This item was rephrased as: 'My energy levels are great'. A more appropriate phrase is 'My energy levels increase easily'. This clearer phrasing of the items in more specific terms to the representative factors may have contributed to better differentiation. The three-factor scale, namely psychological recurrent positive state, social connectedness and physical refreshed energy, indicates reliable Cronbach's alpha above 0.8 . The three factors provide a measure for three of the four enduring personal resources suggested by Fredrickson (2001), namely social, physical and psychological.

Factor one: psychological recurrent positive state measures the continuous reappearance of positive emotional psychological experiences in different situations. This factor supports Luthans and Davis's (1979) notion that emotional responses are controllable through behavioural selfmanagement. It also supports Catalino et al.'s (2014) notion of prioritising positivity, by the daily nurturing of positive emotions. Self-management and nurturing of positive emotions may broaden and strengthen a person's thoughtactions and personal resources (Siu et al., 2015). These nurtured positive thought-actions may cultivate personal strengths (Seligman, 1998, 1999).
Factor two measures social connectedness in the interaction with others as suggested by Fredrickson (2001). This measure supports the argument that more attention to positive emotions leads to endured positive processes (Strauss \& Allen, 2006), higher forms of engagement (Livingstone \& Srivastava, 2012) and self-efficacy, resilience, motivation and coping strategies (Rowe et al., 2015).

The third factor of physical refreshed energy represents enthusiastic energy and inspiration in the work environment. The results regarding this component underpin the view that it is related to opportunities to flourish (Seligman \& Csikszenthmihalyi, 2000), improved capability to adjust, reaching higher forms of positive emotions (Galatzer-Levy et al., 2013), experiencing higher forms of psychological well-being (Smith \& Hollinger-Smith, 2015) and positively influencing the moods of others (Vijayalakshmi \& Bhattacharyya, 2012).

\section{Implications and recommendations for management}

While management should be sensitive to negative emotions and their influence on behaviour in organisations (Kiefer \& Barclay, 2012), the opportunity to investigate positive emotional experiences and their effect on organisational behaviour should be pursued (Steigenberger, 2015). The Positive Emotional Experiences Scale could contribute to the investigation of positive psychology in business research, which seems worth exploring. Investigating the relationship between positive emotional experiences and other work variables could prevent potential pathology (Maddux, 2008), regulate unhealthy moods (Subic-Wrana et al., 2014), acknowledge and promote life satisfaction and subjective well-being (Bastian et al., 2014; Weytens et al., 2014), strengthen personal resources and reduce turnover intention (Siu et al., 2015) and foster an ascending spiral of emotional well-being (Fredrickson \& Joiner, 2002).

The identification of positive emotional experiences has the potential to promote behavioural self-management as advocated by Luthans and Davis (1979) and Davis and Luthans (1980) during the early 1980's. The endorsement of behavioural self-management of positive emotional experiences may prove to be significant to organisational effectiveness. Advocacy of positive emotions has the potential to sensitise organisations to nurture employees' positive emotional experiences which could lead to support of organisational objectives. Such an environment could sensitise individuals to advance and regulate healthy moods (Subic-Wrana et al., 2014), as well as nurture the development of self-enhancement strategies (Ouweneel et al., 2013), leading to improved goal pursuits and growth opportunities (Livingstone \& Srivastava, 2012). These attributes could result in favourable organisational outcomes.

Positive emotional experiences have the potential to improve the psychological climate and relationships between individuals in an organisation (Vijayalakshmi \& 
Bhattacharyya, 2012). It further promises to improve communication, engagement, flexibility and resilience (Rowe et al., 2015). It is therefore important that businesses are aware of employees' work-related well-being (Rothmann et al., 2005) regarding emotional experiences. Application of both the Positive Emotional Experiences and Kiefer and Barclay (2012) Toxic Emotional Experiences Scales can provide a balanced view of both positive and negative emotions of individuals in the work context. These measures could serve as a method to identify and sensitise individuals and organisations to the necessity of improving on positive emotional attributes. Change management strategies could be put into action to salvage negative destructive emotions and support positive emotional outcomes (Steigenberger, 2015). Such an identification could further encourage improvement of positive emotional outcomes as an ideal to strive for.

Organisations should be sensitised to explore opportunities to establish a positive emotional and psychological workplace environment, and the Positive Emotional Experiences Scale can aid this process. Management could use the Positive Emotional Experiences Scale to identify the level of recurrent positive psychological state, social connectedness and refreshed physical energy levels of their employees. Organisations should regard emotions as a critical factor in their overall functioning in promoting employee well-being (Meyers et al., 2013). Businesses cannot ignore the potential effect of emotions on the morale and performance of an organisation. Organisations could be made aware that the mood and emotions of employees potentially have a ripple effect, influencing important strategic areas. By propagating the positive outcomes of positive emotions businesses could create an encouraging work environment that nurtures confidence, progress, optimism and enhanced performance. Organisational intervention should include training in communication techniques and problem-solving skills to improve savouring of positive emotions (Smith \& HollingerSmith, 2015). The capitalisation on positive experiences could enhance overall psychological well-being in a business. Feedback on the value of positive emotional experiences could create an awareness of the development of selfregulation strategies to achieve the desired emotional states (Subic-Wrana et al., 2014). This information could also promote self-enhancement tactics (Ouweneel et al., 2013) to the benefit of the overall welfare of the organisation.

\section{Limitations and implications for future research}

The rephrasing of the Positive Emotional Experiences Scale is only a starting point. The scale signifies the further development of more indicators. Such development should include the intellectual factor prescribed by Fredrickson's (2001) broaden-and-build theory. Similarly items measuring negative intellectual emotions needs to be developed to acknowledge the positive counterpart as suggested by Catalino et al. (2014); Cohrs et al. (2013) and Kiefer and Barclay (2012). Future refinement of this scale should include a thorough theoretical review of positive emotional experiences that could lead to the development of more factors. An improved Positive Emotional Experiences Scale would serve as a broader basis for measuring the relationships with work variables as well as for diagnostic purposes in organisations. The development of such a scale should also measure the convergent and discriminatory validity of the scale. A varied measure of positive emotional experiences could sensitise management in handling challenging organisational situations.

The sample of the current study mainly represents South Africans, which would limit the generalisability of our findings to other cultures. The sample also does not represent the diversity of cultures within the South African context. This Positive Emotional Experiences Scale should be internally and externally validated in more cultures inside and outside the South African context. The next step in the research would be to investigate how well the hypothesised structure replicates with different samples. Furthermore, this Positive Emotional Experiences Scale only measures a limited variety of positive emotions. It does not provide a measure for the fourth personal resource of intellectuality suggested by Fredrickson (2001). Items need to be developed to measure the fourth personal resource suggested by Fredrickson (2001), namely intellectuality on both the positive and negative scales.

Future research may investigate the relationship of positive emotions with other work variables that potentially contribute to improve organisational functioning. The relationship between positive emotional experiences and work-related outcomes such as psychological capital should be explored. Future studies may also investigate factors that improve positive emotional experiences and report on the long-term effect of interventions. Future research could also investigate whether the promotion of positive emotional experiences, and acknowledgement and management of the lack thereof, improve different forms of positive work experiences and reduce turnover and absenteeism.

In light of the warning that negative emotions should not be ignored (Cohrs et al., 2013; Kiefer \& Barclay, 2012; Knyazev et al., 2012), future research should take note of the acknowledgement negative emotional experiences and possible intervention strategies. Investigations could take into account the role that both positive and negative emotions play in rewarding outcomes in the work situation, such as turnover, absenteeism, work engagement, and the psychological capital outcomes of self-efficacy, hopeful behaviour, resilience and optimism. The characteristics of cultural differences in the regulation of positive emotions (Diener et al., 2009; Knyazev et al., 2012; Miyamoto et al., 2014) and negative affect could also be explored. The part that selfregulation strategies (Catalino et al., 2014; Heiy \& Cheavens, 2014), mindfulness and emotional intelligence play in the sustainment of positive emotions, coping strategies and minimising toxic emotions could be examined. Different methods of intervention could be explored to sensitise individuals to use strategies that are aimed at optimally 
solving problematic challenges and decreasing experiences of negative emotions.

\section{Conclusion}

Organisations do not function in a perfect world. However, management should at least attempt to create ideal functioning circumstances. This study broadens the field of positive emotional measures. Positive emotional experiences in the workplace provide the potential for reaching higher levels of operational constructiveness. The Positive Emotional Experiences Scale provides the opportunity to assist individuals and businesses to reflect on their emotional state and implement self-correcting behaviour. The measurement of positive emotions, predictors and outcome variables unconsciously opens up opportunities for solutions. This could encourage businesses to explore strategies for improving positive emotional experiences and for resolving causes of toxic emotional experiences. The identification and nurturing of healthy positive emotional experiences appears instrumental in obtaining positive organisational effects.

\section{Acknowledgements}

My appreciation to the reviewers for valuable feedback.

\section{Competing interests}

The author declares that she has no financial or personal relationships which may have inappropriately influenced her in writing this article.

\section{References}

Axelrod, W. (2015). How exceptional managers use everyday psychology to develop their people. Industrial and Commercial Training, 47(3), 121-126. http://dx.doi. org/10.1108/ICT-11-2014-0075

Baglin, J. (2014). Improving your Exploratory Factor Analysis for ordinal data: A demonstration using FACTOR. Practical Assessment, Research \& Evaluation, 19(5), $1-14$.

Bastian, B., Kuppens, P., De Roover, K., \& Diener, E. (2014). Is valuing positive emotion associated with life satisfaction? Emotion, 14(4), 639-645. http://dx.doi. org/10.1037/a0036466

Byrne, O., \& Shepherd, D.A. (2015). Different strokes for different folks: Engrepreneurial narratives of emotion, cognition, and making sense of business failure. Entrepreneurship Theory and Practice, 44, 375-406. http://dx.doi.org/10.1111/ etap.12046

Cabrera-Nguyen, P. (2010). Author guidelines for reporting scale development and validation results. Journal of the Society for Social Work and Research, 1(2), 99-103. http://dx.doi.org/10.5243

Catalino, L.I., Algoe, S.B., \& Fredrickson, B.L. (2014). Prioritizing positivity: An effective approach to pursuing happiness? Emotion, 14(6), 1155-1161. http://dx.doi. org/10.1037/a0038029

Cavanaugh, L.A., Bettman, J.R., \& Luce, M.F. (2015). Feeling love and doing more for distant others: Specific positive emotions differentially affect prosocia consumption. Journal of Marketing Research, 52, 657-673. http://dx.doi. org/10.1509/jmr.10.0219

Cohrs, J.C., Christie, D.J., White, M.P., \& Das, C. (2013). Contributions of positive psychology to peace: Toward global well-being and resilience. The American Psychologist, 68(7), 590-600. http://dx.doi.org/10.1037/a0032089

Collins, A.L., Jordan, P.J., Lawrence, S.A., \& Troth, A.C. (2016). Positive affective tone and team performance: The moderating role of collective emotional skills. Cognition and Emotion, 30(1), 167-182. http://dx.doi.org/10.1080/02699931. 2015.1043857

Costello, A.B., \& Osborne, J.W. (2005). Best practices in exploratory factor analysis: Four recommendations for getting the most from your analysis. Practical Assessment, Research \& Evaluation, 10(7), 1-9.

Davis, T.I.M.R.V, \& Luthans, F. (1980). A social learning approach to organizational behavior. Academy of Management Review, 5(2), 281-290.

Diener, E., Wirtz, D., Biswas-Diener, R., Tov, W., Kim-Prieto, C., Choi, D.-W., et al. (2009). Assessing well-being. Social Indicators Research Series, 39, 247-266. http://dx.doi.org/10.1007/978-90-481-2354-4
Fischer, M. (2014). Positive emotions foster the co-creation of mutual value in services: Four positively deviant performances. In N.M. Ashkanasy, W.J. Zerbe, \& C.E.J. Hartel (Eds.), Emotions and the organizational fabric (pp. 13-47). Bingley: C.E.J. Harte
Emerald.

Fredrickson, B.L. (2001). The role of positive emotions in positive psychology: The broaden-andbBuild theory of positive emotions. American Psychologist, 56(3), 218-226. http://dx.doi.org/10.1037/0003-066X.56.3.218

Fredrickson, B.L., \& Joiner, T. (2002). Positive emotions trigger upward spirals toward emotional well-being. Psychological Science, 13(2), 172-175. http://dx.doi. org/10.1111/1467-9280.00431

Fredrickson, B.L., \& Kurtz, L.E. (2011). Cultivating positive emotions to enhance human flourishing. In S.I. Donaldson, M. Csikszenthmihalyi, \& J. Nakamura (Eds.), Applied positive psychology: Improving everyday life, health, schools, work, and society (pp. 35-47). New York: Routhledge.

Galatzer-Levy, I.R., Brown, A.D., Henn-Haase, C., Metzler, T.J., Neylan, T.C., \& Marmar, C.R. (2013). Positive and negative emotion prospectively predict trajectories of resilience and distress among high-exposure police officers. Emotion, 13(3), 545-553. http://dx.doi.org/10.1037/a0031314

Gruber, J., Hay, A.C., \& Gross, J.J. (2014). Rethinking emotion: Cognitive reappraisal is an effective positive and negative emotion regulation strategy in bipolar disorder. Emotion, 14(2), 388-396. http://dx.doi.org/10.1037/a0035249

Gruber, J., Oveis, C., Keltner, D., \& Johnson, S.L. (2011). A discrete emotions approach to positive emotion disturbance in depression. Cognition and Emotion, 25(1) 40-52. http://dx.doi.org/10.1080/02699931003615984

Heiy, J.E., \& Cheavens, J.S. (2014). Emotion back to basics : A naturalistic assessment of the experience and regulation of emotion. Emotion, 14(5), 878-891. http:// dx.doi.org/10.1037/a0037231

Jackson, D.C., Malmstadt, J.R., Larson, C.L., \& Davidson, R.J. (2000). Suppression and enhancement of emotional responses to unpleasant pictures. Psychophysiology, 37(4), 515-522.

Kaplan, S., Bradley-Geist, J.C., Ahmad, A., Anderson, A., Hargrove, A.K., \& Lindsey, A. (2014). A test of two positive psychology interventions to increase employee wellbeing. Journal of Business and Psychology, 29, 367-380. http://dx.doi. org/10.1007/s10869-013-9319-4

Kiefer, T., \& Barclay, L.J. (2012). Understanding the mediating role of toxic emotional experiences in the relationship between negative emotions and adverse outcomes. Journal of Occupational and Organizational Psychology, 85(4), 600625. http://dx.doi.org/10.1111/j.2044-8325.2012.02055.x

Kim, S.H., \& Hamann, S. (2007). Neural correlates of positive and negative emotion regulation. Journal of Cognitive Neuroscience, 19(5), 776-798. http://dx.doi. org/10.1162/jocn.2007.19.5.776

Knyazev, G.G., Barchard, K.A., Razumnikova, O.M., \& Mitrofanova, L.G. (2012). The relationship of positive and negative expressiveness to the processing of emotion information. Scandinavian Journal of Psychology, 53(3), 206-215. http://dx.doi. org/10.1111/j.1467-9450.2012.00941.x

Koskina, A., \& Keithley, D. (2010). Emotion in a call centre SME: A case study of positive emotion management. European Management Journal, 28(3), 208-219. http://dx.doi.org/10.1016/j.emj.2009.11.003

Levine, L.J., Schmidt, S., Kang, H.S., \& Tinti, C. (2012). Remembering the silver lining: Reappraisal and positive bias in memory for emotion. Cognition \& Emotion, 26(5) 871-884. http://dx.doi.org/10.1080/02699931.2011.625403

Liang, S.-G., \& Steve Chi, S.-C. (2013). Transformational leadership and follower task performance: The role of susceptibility to positive emotions and follower positive emotions. Journal of Business and Psychology, 28, 17-29. http://dx.doi. org/10.1007/s10869-012-9261-x

Lindebaum, D., \& Jordan, P.J. (2012). Where are you going? A comparative analysis of job and career change intentions among USA it workers. Journal of Organizational Behavior, 33, 1027-1030. http://dx.doi.org/10.1002/job.1819

Livingstone, K.M., \& Srivastava, S. (2012). Up-regulating positive emotions in everyday life: Strategies, individual differences, and associations with positive emotion and well-being. Journal of Research in Personality, 46(5), 504-516. http://dx.doi. org/10.1016/j.jrp.2012.05.009

Luthans, F. (2002). Positive organizational behavior: Developing and managing psychological strengths. Academy of Management Executive, 16(1), 57-72. http:// dx.doi.org/10.5465/AME.2002.6640181

Luthans, F. (2012). Psychological capital : Implications for HRD, retrospective analysis, and future directions, Human Resource Development Quarterly 23(1), 1-8. http:// dx.doi.org $/ 10.1002 / \mathrm{hrdq}$

Luthans, F., Avey, J.B., Clapp-Smith, R., \& Li, W. (2008). More evidence on the value of Chinese workers' psychological capital: A potentially unlimited competitive resource? The International Journal of Human Resource Management, 19(5), 818-827. http://dx.doi.org/10.1080/09585190801991194

Luthans, F., Avolio, B., Avey, J.B., \& Norman, S.M. (2007a). Psychological capital: Measurement and relationship with performance and job satisfaction. Personne Psychology, 60, 541-572. http://dx.doi.org/10.1111/j.1744-6570.2007.00083.x

Luthans, F., Avolio, B.J., Avey, J.B., \& Norman, S.M. (2007b). Positive psychological capital: Measurement and relationship with performance and satisfaction. Personnel Psychology, 60(3), 541-572. http://dx.doi.org/10.1111/j.1744-6570. 2007.00083.x

Luthans, F., Youssef, C., \& Avolio, B. (2007). Psychological capital: Developing the human competitive edge. Cary, NC, USA: Oxford Uninversity Press.

Luthans, F., \& Davis, T.R.V. (1979). Behavioral self- managemeni - The missing link in managerial effectiveness. Organizational Dynamics, 8(1), 42-60. http://dx.doi. org/10.1016/0090-2616(79)90003-2 
Luthans, F., Luthans, K.W., \& Luthans, B.C. (2004). Positive psychological capital Beyond human and social capital. Business Horizons, 47(1), 45-50. http://dx.doi. org/10.1016/j.bushor.2003.11.007

Luthans, F., Youssef, C., \& Avolio, B. (2007). Psychological capital: Developing the human competitive edge. Cary, NC: Oxford Uninversity Press.

Maddux, J.E. (2008). Positive psychology and the illness ideology: Toward a positive clinical psychology. Applied Psychology, 57, 54-70. http://dx.doi.org/10.1111/ j.1464-0597.2008.00354.x

Meyers, M.C., Van Woerkom, M., \& Bakker, A.B. (2013). The added value of the positive: A literature review of positive psychology interventions in organizations. European Journal of Work and Organizational Psychology, 22(5), 618-632. http:// dx.doi.org/10.1080/1359432X.2012.694689

Miyamoto, Y., Ma, X., \& Petermann, A.G. (2014). Cultural differences in hedonic emotion regulation after a negative event. Emotion, 14(2), 1-12. http://dx.doi. org/10.1037/a0036257

Onkila, T. (2015). Pride or embarrassment? Employees emotions and corporate social responsibility. Corporate Social Responsibility and Environmental Management 22, 222-236. http://dx.doi.org/10.1002/csr.1340

Ouweneel, E., Le Blanc, P.M., \& Schaufeli, W.B. (2013). Do-it-yourself: An online positive psychology intervention to promote positive emotions, self-efficacy, and engagement at work. Career Development International, 18(2), 173-195. http:// engagement at work. Career Developm

Ouweneel, E., Le Blanc, P.M., \& Schaufeli, W.B. (2014). On being grateful and kind Results of two randomized controlled trials on study-related emotions and academic engagement. Journal of Psychology, 148(1), 37-60. http://dx.doi.org/ 10.1080/00223980.2012.742854

Pallant, J. (2016). SPSS survival manual. A step by step buide to data analysis using IBM SPSS. (6th edn.). New York: Open University Press.

Quinones, C., Rodriguez-Carvajal, R., Clarke, N., \& Griffiths, M.D. (2016). Cross-cultura comparison of Spanish and British 'service-with-a-smile' outcomes. Journal of Managerial Psychology, 31(5), 960-975. http://dx.doi.org/10.1108/JMP-042015-0128

Rothmann, S., Steyn, L.J., \& Mostert, K. (2005). Job stress, sense of coherence and work wellness in an electricity supply organisation. South African Journal of Business Management, 36(1), 55-63.

Rowe, A.D., Fitness, J., \& Wood, L.N. (2015). University student and lecturer perceptions of positive emotions in learning. International Journal of Qualitative Studies in Education, 28(1), 1-20. http://dx.doi.org/10.1080/ 09518398.2013.847506

Saunders, M., Lewis, P., \& Thornhill, A. (2012). Research methods for business students. (5th edn.). Harlow: Pearson.

Seligman, M.E.P. (1998). Positive social science. APA Monitor, 29, 5.

Seligman, M.E.P. (1999). President's address. American Psychologist, 54, 559-562.

Seligman, M.E.P., \& Csikszenthmihalyi, M. (2000). Positive psychology: An introduction. American Psychologist, 55(1), 5-14. http://dx.doi.org/10.1037//0003-066X.55.1.5

Siu, O.L., Cheung, F., \& Lui, S. (2015). Linking positive emotions to work well-being and turnover intention among Hong Kong police officers: The role of psychological capital. Journal of Happiness Studies, 16, 367-380. http://dx.doi.org/10.1007/ s10902-014-9513-8

Smith, J.L., \& Hollinger-Smith, L. (2015). Savoring, resilience, and psychological wellbeing in older adults. Aging \& Mental Health, 19(3), 192-200. http://dx.doi.org/ 10.1080/13607863.2014.986647
Steigenberger, N. (2015). Emotions in sensemaking: A change management perspective. Journal of Organizational Change Management, 28(3), 1-31. http:// dx.doi.org/10.1108/JOCM-05-2014-0095

Stephens, J.P., \& Carmeli, A. (2016). The positive effect of expressing negative emotions on knowledge creation capability and performance of project teams. International Journal of Project Management, 34, 862-873. http://dx.doi. org/10.1016/j.ijproman.2016.03.003

Strauss, G.P., \& Allen, D.N. (2006). The experience of positive emotion is associated with the automatic processing of positive emotional words. The Journal of Positive Psychology, 1(3), 150-159. http://dx.doi.org/10.1080/17439760600566016

Subic-Wrana, C., Beutel, M.E., Brähler, E., Stőbel-Richter, Y., Knebel, A., Lane, R.D., et al. (2014). How is emotional awareness related to emotion regulation strategies and self-reported negative affect in the general population? PLos One, 9(3), 1-10. http://dx.doi.org/10.1371/journal.pone.0091846

Tabachnick, B.G., \& Fidell, L.S. (2014). Principal Components and Factor Analysis. In B.G. Tabachnick \& L.S. Fidell (Eds.), Using multivariate statistics (6th edn., pp. 659-730). Edinburg Gate: Person Education Ltd.

Todorova, G., Bear, J.B., \& Weingart, L.R. (2014). Can conflict be energizing? A study of task conflict, positive emotions, and job satisfaction. Journal of Applied Psychology, 99(3), 451-467. http://dx.doi.org/10.1037/a0035134

Tse, H.H.M., \& Dasborough, M.T. (2008). A study of exchange and relationships. Group \& Organization Management, 33(2), 194-215. http://dx.doi.org/10.1177/ 1059601106293779

Van Laarhoven, A.I.M., Walker, A.L., Wilder-Smith, O.H., Kroeze, S., Van Riel, P.L.C.M. Van de Kerkhof, P.C.M., et al. (2012). Role of induced negative and positive emotions
in sensitivity to itch and pain in women. The British Journal of Dermatology, 167(2), in sensitivity to itch and pain in women. The British Journal of Derm
262-269. http://dx.doi.org/10.1111/j.1365-2133.2012.10933.x

Vijayalakshmi, V., \& Bhattacharyya, S. (2012). Emotional contagion and its relevance to individual behavior and organizational processes: A position paper. Journal of Business and Psychology, 27, 363-374. http://dx.doi.org/10.1007/s10869-011-9243-4

Watson, D., Clark, L.A., \& Tellegen, A. (1988). Positive and negative affect schedule (PANAS). Journal of Personality and Social Psychology, 54(6), 1063-1070. http:// dx.doi.org/10.1037/0022-3514.54.6.1063

Weytens, F., Luminet, O., Verhofstadt, L.L., \& Mikolajczak, M. (2014). An integrative theory-driven positive emotion regulation intervention. PLoS One, 9(4), e95677. http://dx.doi.org/10.1371/journal.pone.0095677

Worthington, R.L., \& Whittaker, T.A. (2006). Scale development research: A content analysis and recommendations for best practices. The Counseling Psychologist, 34(6), 806-838. http://dx.doi.org/10.1177/0011000006288127

Xu, Y., Yu, Y., Xie, Y., Peng, L., Liu, B., Xie, J., et al. (2015). Positive affect promotes wellbeing and alleviates depression: The mediating effect of attentional bias. Psychiatry Research, 228(3), 482-487. http://dx.doi.org/10.1016/j.psychres.2015. 06.011

Xue, S., Cui, J., Wang, K., Zhang, S., Qiu, J., \& Luo, Y. (2013). Positive emotion modulates cognitive control: An event-related potentials study. Scandinavian Journal of Psychology, 54(2), 82-88. http://dx.doi.org/10.1111/sjop.12031

Yang, I., \& Kelly, A. (2016). The positive outcomes of 'socially sharing negative emotions' in workteams: A conceptual exploration. European Management Journal, 34(2), 172-181. http://dx.doi.org/10.1016/j.emj.2015.10.005

Yang, L.Q. Simon, L.S., Wang, L., \& Zheng, X. (2016). To branch out or stay focused? Affective shifts differentially predict organizational citizenship behavior and task performance. The Journal of Applied Psychology, 101(6), 831-845. http://dx.doi. performance. The Journal
org/10.1037/apl0000088 